\title{
Analysis of the peak vertical displacement of liquid surface due to sloshing
}

\author{
Kamila Kotrasova ${ }^{1, *}$, Eva Kormanikova ${ }^{1}$ and Iveta Hegedusova ${ }^{1}$ \\ ${ }^{1}$ Technical University of Kosice, Faculty of Civil Engineering, Institute of Structural Engineering, \\ 04200 Kosice, Slovak Republic
}

\begin{abstract}
When a tank containing liquid vibrates, the liquid exerts hydrodynamic effects on the solid domain of a tank. In the case of roof tanks, a large sloshing wave will impact the wall or roof of the tanks and may cause extensive damage or failure of the tanks. This paper provides the theoretical background of simplified seismic analysis of liquid storage cylindrical ground -supported tanks, and it documents the seismic effect of input motions characteristics on fluid sloshing behaviour.
\end{abstract}

\section{Introduction}

The cylindrical tanks are used to store a variety of liquids, e.g. water for drinking and firefighting, petroleum, chemicals, and liquefied natural gas [1].

The behaviour of subjected to earthquake induced fluid pressured was probably first studied Westergaard. Jacobsen analysed a rigid cylindrical liquid containing tank and cylindrical pier surrounded by liquid, subjected to horizontal accelerations [2]. Subsequently, Housner simplified the method of analysis and introduced the concept of two components of dynamic pressures, impulsive and convective. In subsequent work, Housner, Haround, Velestos and others modified the tank model to account for the flexibility of the tank walls [3-8].

When a tank containing liquid vibrates, the liquid exerts hydrodynamic effects on the solid domain of a tank, in addition to the hydrostatic effect [9-12]. The earthquake induces liquid sloshing in a tank. The number of extensive studies have been performed on the sloshing behaviour under earthquake ground excitation. The many liquid tanks have been severely damaged or have totally failed in past major earthquakes. Post-earthquake reconnaissance reports have indicated that liquid sloshing is one of the major causes of serious damage in a tank and the environment during earthquakes [13-16]. For open tanks with an insufficient freeboard, a liquid material such as oil and chemical fluids may overflow into the surrounding area and result in the contamination of the soil. In the case of roof tanks, a large sloshing wave will impact the wall or roof of the tanks and may cause extensive damage or failure of the tanks [17-19].

The typical collapse modes of cylindrical tanks subjected to horizontal seismic motions are:

\footnotetext{
* Corresponding author: kamila.kotrasova@tuke.sk
} 
- elephant-foot bulge which develops at the lowest circumference of the tank wall. The elephant-foot bulge is a phenomenon like buckling taking place under a combined action of normal compressive stress associated with the overturning moment acting on the cylinder and the hoop stress caused by the internal liquid pressure at the lowest part of cylindrical walls,

- up-lift of bottom plate, the vertical load on the side wall of the cylindrical tank is only its own weight. Therefore, when tank is not anchored at the base, the base of side wall can easily lift under the horizontal seismic loading. Since the cylindrical part has hight vertical stiffness, the thank shows an overall displacement, which is characterized by rotational displacement of the tank wall as a rigid bode,

- in the case of roof tanks, a large sloshing wave will impact the wall or roof of the tanks and may cause extensive damage or failure of the tanks.

Numerous papers have reported on the sloshing response in a ground supported tank subjected to earthquake ground motions. Nevertheless, up to now the sloshing response for earthquake excitation has not been properly predicted in many cases [20-23]. The reason for this is that past research has focused only on the configuration of tanks and the dynamic properties of fluid motion even though the sloshing behaviour of a tank is very sensitive to the characteristics of the input motions as well as the configuration of the tank-liquid system $[24,25]$. Therefore, to evaluate and predict the sloshing response of liquid storage tanks reasonably, extensive investigations should be given to the effect of the characteristics of input motions on sloshing behaviour.

\section{Seismic design of liquid storage tanks}

When a tank containing liquid vibrates in horizontal direction, the liquid exerts hydrodynamic effects on the solid domain of a tank, in addition to the hydrostatic effect. Seismic design of the liquid storage tanks has been adopted in [20]. The dynamic analysis of a liquid - filled tank may be carried out using the concept of generalized the single degree of freedom (SDOF) systems representing the impulsive and convective modes of vibration of the tank - liquid system. For practical applications, only the first convective mode of vibration needs to be considered in the analysis (Fig. 1) [7, 8].
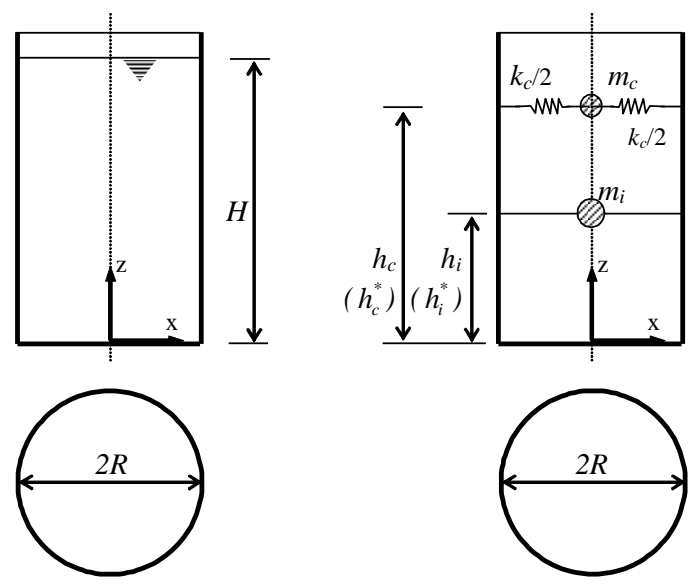

Fig. 1. Two single degree of freedom systems for ground supported cylindrical tank. 
For a ground supported cylindrical tank, in which the wall is rigidly connected with the base slab, the natural period of the impulsive mode of vibration $T_{i}$, in seconds, is given by

$$
T_{i}=C_{i} \frac{H \sqrt{\rho}}{\sqrt{s / R} \sqrt{E}}
$$

where $H$ is height to the free surface of the liquid; $R$ is tank's radius; $s$ is equivalent uniform thickness of the tank wall; $\rho$ is mass density of liquid of tank material; $E$ is Modulus of elasticity of tank material; $C_{i}$ is the dimensionless coefficient [9].

The natural period of the convective mode of vibration $T_{c}$, in seconds, is given by

$$
T_{c}=C_{c} \sqrt{R}
$$

where $C_{c}$ is the coefficient is expressed in $s / \sqrt{m},[10]$.

Total base shear of ground supported tank at the bottom of the wall can be also obtained by base shear in impulsive mode and base shear in convective mode:

$$
V=\left(m_{i}+m_{w}+m_{r}\right) S_{e}\left(T_{i}\right)+\left(m_{c}\right) S_{e}\left(T_{c}\right)
$$

The overturning moment of ground supported tank immediately above the base plate is given also by

$$
M=\left(m_{i} h_{i}+m_{w} h_{w}+m_{b} h_{b}+m_{r} h_{r}\right) S_{e}\left(T_{i}\right)+\left(m_{c} h_{c}\right) S_{e}\left(T_{c}\right)
$$

and the overturning moment of ground supported tank immediately below the base plate is given also by

$$
M^{*}=\left(m_{i} h_{i}^{*}+m_{w} h_{w}+m_{b} h_{b}+m_{r} h_{r}\right) S_{e}\left(T_{i}\right)+\left(m_{c} h_{c}^{*}\right) S_{e}\left(T_{c}\right)
$$

where $m_{i}$ is the impulsive mass of fluid, $m_{c}$ is the convective mass of fluid connected to tank wall by springs $k_{c}=0.836 \cdot \mathrm{mg} H \cdot\left(\tanh ^{2}(1.84 \cdot H / D)\right)$ [26]; $h_{i}$ and $h_{i}^{*}$ are the heights of wall pressure resultant for the impulsive component, see Fig. $1[7,26] ; h_{c}$ and $h_{c}^{*}$ are the heights of wall convective pressure resultant, see Fig. 1 [7,26]; $S_{e}\left(T_{i}\right)$ is impulsive spectral acceleration obtained from a $2 \%$ damped elastic response spectrum; $S_{e}\left(T_{c}\right)$ is convective spectral acceleration obtained from a $0.5 \%$ damped elastic response spectrum; $m_{w}$ is mass of the tank wall; $m_{b}$ is mass of the tank base plate; $m_{r}$ is mass of the tank roof; $h_{w}$ is the height of center of gravity of wall mass; $h_{w b}$ and $h_{r}$ are the heights of center of gravity of base plate mass and of roof mass.

The peak vertical displacement of the liquid surface due to sloshing is given

$$
d_{\max }=R \cdot S_{c}\left(T_{c}\right) / g
$$

\section{Experiment and results}

The steel ground supported cylindrical tank of $1608 \mathrm{~m} 3$ capacity with the diameter $2 R=16$ $\mathrm{m}$ and the total height $H_{w}=9.0 \mathrm{~m}\left(E=2.1 \cdot 10^{11} \mathrm{Nm}^{-2}, \rho=7890 \mathrm{~kg} / \mathrm{m}^{3}\right)$ is fully anchored to a concrete foundation. The tank wall and tank bottom have uniform thickness $0.01 \mathrm{~m}$. The total mass of the tank wall is $m_{w}=35.7 \cdot 10^{3} \mathrm{~kg}$, and the total mass of the tank bottom is $m_{b}=15.9 \cdot 10^{3} \mathrm{~kg}$. The mass of the tank roof $m_{r}=21 \cdot 10^{3} \mathrm{~kg}$, and the height of centre gravity $\left(h_{r}\right)$ is $8.0 \mathrm{~m}$. The tank is filled with water to the height $H$ of $8.1 \mathrm{~m}$ (the tank slenderness parameter $\gamma=H / R=0.5)$, the total mass of water in the tank is $1.6 \cdot 10^{6} \mathrm{~kg}\left(\rho=1000 \mathrm{~kg} / \mathrm{m}^{3}\right)$.

The ground motions loading is simulated by the elastic response spectrum determined for the Slovakia region with $a_{g}=1.0 \mathrm{~ms}^{2}$ considering the B category subsoil (very dense sand, 
gravel, or very stiff clay, at least several tens of metres in thickness, characterised by a gradual increase of mechanical properties with depth).

Fig. 2 documents the seismic responses of the steel cylindrical tank: the total base shears $Q$, the total bending moments $M$ and the total overturning moments $M^{*}$ in depending on the ground accelerations $a_{g}$ and their proportional dependence. The seismic responses of the fluid filling of steel cylindrical tank: the liquid peak vertical displacements $d_{\max }$ is documented in Fig. 3 on depending on the ground acceleration $a_{g}$ and the convective spectral acceleration obtained from a $0.5 \%$ damped elastic response spectrum $S_{e}\left(T_{c}\right)$.

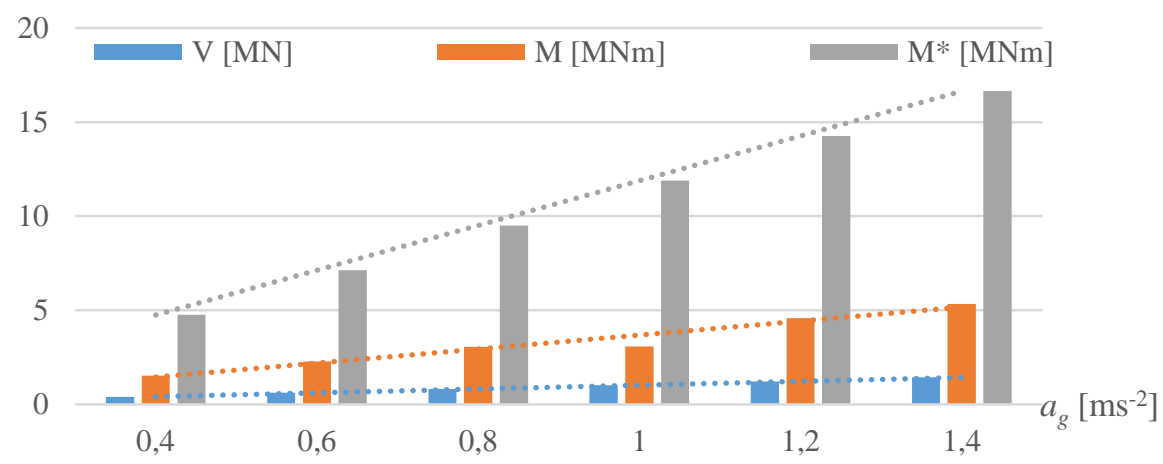

Fig. 2. Comparison of the total base shear, the total bending moment and the total overturning moment in depending on $a_{g}$.

a)

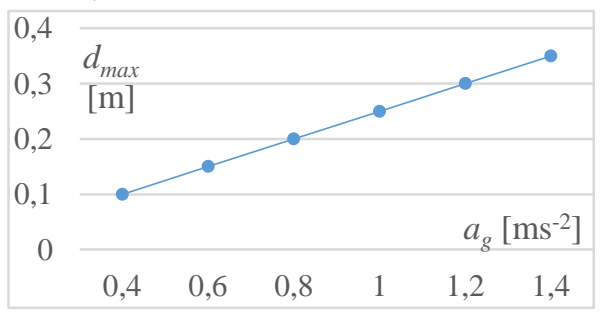

b)

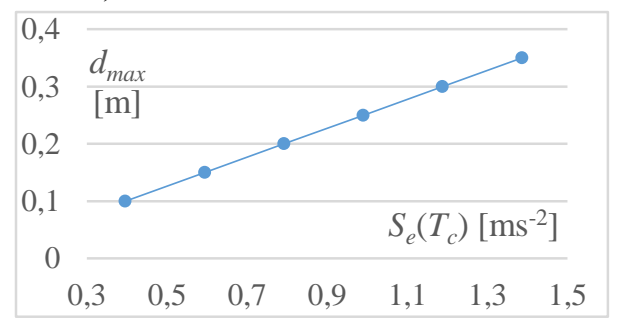

Fig. 3. Comparison of the liquid peak vertical displacement $d_{\max }$ in depending on a) $a_{g}$.and b) $S_{e}\left(T_{c}\right)$.

\section{Conclusion}

The steel ground supported cylindrical tank fully anchored to a concrete foundation was analysed. The effect of the characteristics of input motions on sloshing behaviour was analysed and documented. It is seen that influence motion characteristics have proportional on seismic response of fluid filled tank: the total base shear, the total bending moment, total overturning moment and the liquid peak vertical displacement. It is due, that the values of elastic response spectrum are in the proportional region of the elastic spectrum for considered tank. In the case of other tanks with different tank slender parameter may the values of elastic response spectrum give onto other parts of the elastic response spectrum that is not so proportional. These dependencies will be analysed in further studies. 
This work was supported by the Scientific Grant Agency of the Ministry of Education of Slovak Republic and the Slovak Academy of Sciences under Projects VEGA 1/0374/19.

\section{References}

1. Y S. Choun, 15 WCEE, Lisboa (2012)

2. V. Vukobratovic, D. Ladinovic, ICET-2013, Serbia, paper No. T.3-1.2 (2013)

3. K. Kotrasová, Procedia Engineering. 190, 2-6 (2017)

4. V. Michalcova, L. Lausova, I. Skotnicova, Procedia Engineering. 190, 134-139 (2017)

5. V. Michalcová, L. Lausová, Computers and Structures. 207, 187-193 (2017)

6. K. Kotrasová, E. Kormaníková, Advances in Mathematical Physics. 2017, 1-9 (2017)

7. P. K. Malhotra: Journal of structural engineering 405-414 (1997)

8. STN EN 1998-4. Eurocode 8: Design of structure for earthquake resistance - Part. 4: Silos, tanks and pipelines. 2006

9. L. Uhlířová, N. Jendželovský, Vibroingeneering Procedia, 23, 99-104 (2019)

10. J. Králik, MATEC Web of Conferences. 107, 1-8 (2017)

11. M. Krejsa, P. Janas, V. Krejsa, International Journal of Mathematics and Computers in Simulation. 8, 1, 121-126 (2014)

12. M. Major, K. Kuliński, I. Major, Procedia Engineering. 190, 231-236 (2017)

13. K. Kotrasová, I. Grajciar, E. Kormaníková, Journal of Vibration Engineering and Technologies. 3, 3, 315-330 (2015)

14. P. Kuklik, M. Broucek, M. Kopackova, Structural engineering and mechanics. 33, 5, 635-647 (2009)

15. K. Kotrasova, E. Kormanikova, International Journal of Mechanics. 10, 242-252 (2016)

16. K. Kotrasova, Advanced Materials Research. 969, 320-323 (2014)

17. J. Melcer, AIP Conference Proceedings. Vol. 1978. 150004, (2017)

18. K. Kotrasová, I. Grajciar, Advanced Materials Research. 969, 119-124 (2014)

19. K. Kotrasová, E. Kormaníková, Key Engineering Materials. 635, 147-150 (2015)

20. G. W. Housner, https://authors.library.caltech.edu/48022/1/15.full.pdf

21. H. Sezen, R. Livaoğlu, A. Doğangün, Engineering Structure, 30, 794-803 (2008)

22. O. Sucharda, J. Brozovsky, 7, 3, 192-200 (2013)

23. M. Mocilan, M, Zmindak, P. Pastorek, 136, 45-49 (2016)

24. K. Tvrdá, MATEC Web of Conferences. 107 (2017)

25. STN EN 1998-1. Eurocode 7: Design of structure for earthquake resistance - Part. 1: General rules, seismic actions and rules for buildings. 2004

26. IITK-GSDMA: Guidelines for seismic design of liquid storage tanks - provisions with commentary and explanatory examples. Kanpur, Indian Institute of Technology Kanpur (2005) 